\title{
Talking with pediatric patients with overweight or obesity and their parents: perceived self-efficacy and barriers of Dutch healthcare professionals from seven different professions. A self-report study
}

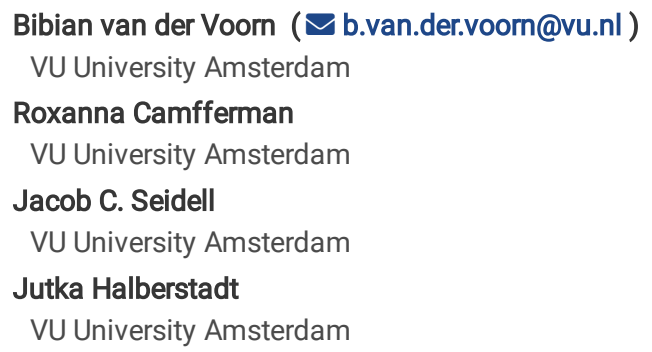




\section{Abstract}

Background: Many healthcare professionals (HCPs) feel uncomfortable and incompetent to talk about weight with children with overweight and obesity and their parents. To optimally target interventions that can improve obesity care for children, we assessed the self-efficacy (SE) and perceived barriers (PBs) of Dutch HCPs in regard to talking about weight and lifestyle when treating children with overweight or obesity. In addition, we analyzed interdisciplinary differences.

Methods: A newly developed, practice- and literature-based questionnaire was completed by 578 HCPs of 7 different professions. Kruskal-Wallis, t-tests and chi-square tests were used to analyze interdisciplinary differences on SE, PBs and the effort to discuss weight and lifestyle despite barriers.

Results: On average for the total group, the reported strength of SE was 7.2 (range 3-10; scale 1-10), and the median number of different PBs was 4.0 (range $0-12$; out of 17). The majority of HCPs (94.6\%) reported that they perceived one or more barriers.

HCPs who perceived too many barriers to discuss the weight and lifestyle of the child in the majority of cases (9.6\%), reported a lower SE (mean 6.3), as compared to professionals who were likely to discuss these topics (mean SE $7.3 p<0.01$ ), although a similar number of PBs. In total, $14.2 \%$ ( $n=82$ ) of all HCPs either rated their SE below 5 or reported that they did not address weight and lifestyle due to PBs in the majority of cases.

Conclusions: Although on average Dutch HCPs rated their self-efficacy fairly good, for a subgroup major improvements are necessary to lower perceived barriers and improve their self-efficacy, aiming to improve the quality of care for Dutch children with obesity.

\section{Background}

In 2020, as many as $14.7 \%$ of Dutch children (4-18 year) had overweight, of which $2.5 \%$ had obesity (1). To discuss effectively weight and lifestyle with these children and their primary caregivers (in most cases parents), healthcare professionals (HCPs) are required to have specific knowledge, skills and attitude (2-5). However, many HCPs report that they feel uncomfortable and incompetent to talk about weight and lifestyle and often avoid weightrelated topics or only refer to them indirectly (5-7), suggesting a low self-efficacy (SE). In addition to these internal barriers, also external, i.e. organizational and societal, barriers interfere with optimal obesity care for children (6-8). Therefore, studies advocate to invest in obesity education programs, along with the organization of an adequate financial and infrastructural framework essential for adequate long-term obesity care (8-10).

Perceived SE is influenced by multiple internal and external factors, including how the individual perceives one's knowledge, previously acquired skills, emotional wellbeing, task complexity, professional role and available time (11-13). In this manuscript, SE would refer to a person's perceived capability to successfully address weight and lifestyle when treating children with overweight or obesity and their parents. Someone assesses their SE by analyzing the internal and external factors that are involved in one's task-specific capability, i.e. a combination of perceived barriers (PBs) (11, 13). Although someone's behavior is influenced by more factors than SE alone, such as motivation, SE can predict one's intentions and moderates behavioral choices and commitment $(11,13)$. Accordingly, an increased SE, which can result from training $(14-16)$ could help HCPs to overcome the barriers they perceive.

To optimally target interventions that can improve obesity care for children, we assessed the SE and PBs of Dutch HCPs that treat children with overweight and obesity, in regard to talking about weight and lifestyle. In addition, we analyzed how these vary across different types of HCPs.

\section{Methods}

\subsection{Aim, design and setting of the study}

The aim of this study was to assess how HCPs that work within different levels of pediatric obesity care perceive their self-efficacy and barriers they face when talking about weight and lifestyle with children with overweight or obesity and their parents. In addition, we assessed whether this affected the effort they put into starting the conversation despite barriers.

This observational, self-report study was conducted nationwide, in 2018. HCPs that worked in care for children and adolescents with overweight or obesity were recruited through their professional associations, at conferences, through personal contacts, and through public health services. For this purpose, seven groups of HCPs were included: General Practitioners (GPs), Youth Health-care Physicians (YHCPs), Youth Health-care Nurses (YHCNs), pediatricians, mental health professionals, dieticians and physiotherapists.

\subsection{Participants and procedure}

In total, $696 \mathrm{HCPs}$, from all levels of health care returned their questionnaire. For this study we included participants that worked within the 7 professions depicted above (excluding $n=103$ ) and completed at least one question (excluding $n=15$ ), leaving a total of 578 HCPs.

\subsection{Measurements}

2.3.1 Self-efficacy. SE was self-reported with a score between ' 1 ' and ' 10 ' on the question: 'How confident do you feel in discussing weight and lifestyle with children and their parents?'. A score of ' 1 ' represented low self-efficacy and '10' represented high self-efficacy.

Page 2/9 
2.3.2 Perceived Barriers. A new questionnaire was developed, based upon the literature (see supplementary file 1), that was used to ask what barriers HCPs perceived when discussing weight and lifestyle with children with overweight or obesity and their parents. Table 3 gives an overview of the 16 barriers that were included. HCPs were asked which of the barriers were applicable in their work. The barriers were scored dichotomously: ' 0 '= Not Applicable and ' 1 ' = Applicable. In addition, HCPs were given the opportunity to provide an additional barrier that were not included in the questionnaire. Accordingly, a maximum of 17 barriers could be scored, in total, of which 16 were presented as a single choice question and one open-ended.

Furthermore, HCPs were asked how often they avoid to discuss weight and lifestyle due to PBs when they interact with a child with overweight or obesity and their parents. The following multiple-choice (single answer) options were offered: ' 1 ' = Never, I always discuss weight, ' 2 ' = In less than a quarter of the cases I do not discuss weight, ' 3 ' = In about half of the cases I do not discuss weight, ' 4 ' = In three quarters of the cases I do not discuss weight, and ' 5 ' = I never discuss weight. Subsequently, answers were dichotomized: ' 0 ' = Almost always discusses weight and lifestyle (option 1 and 2 ) and ' 1 ' = Often not discusses weight and lifestyle (option 3,4 and 5).

Perceived weight bia s in health care. This measure, created for the purposes of the study, queried participants about their per-ceptions of weight bias expressed by peers, educators, and health providers in the medical environment. Participants were asked to indicate, on a 5-point Likert scale, ranging from "strongly disagree" to "strongly agree," how much they agreed with each of seven state-ments (e.g., "I have heard/witnessed health care providers making negative comments or jokes about obese patients"). The develop-ment of these statements was guided from qualitative research with focus groups of medical students reported in previous research (26).

\subsection{Statistical analyses}

For the statistical analyses, IBM SPSS 27.0 was used. First, descriptive statistics were conducted to summarize the reported strength of SE and number of PBs for each group of HCPs separately and for the total group. Second, Kruskal Wallis tests were computed to assess interdisciplinary differences on reported strength of SE and number of PBs. Third, frequencies of each barrier were computed for each professional group and the total group of professionals. Fourth, Fisher's exact tests were calculated to assess the relationship between discussing weight (almost always vs. often not) and each PB (not applicable vs. applicable). Fifth, a t-test was done to assess the difference between the HCPs who often do not discuss weight vs. HCPs who almost always discuss weight on their reported strength of SE. Sixth, the influence of confounding factors was investigated using multivariate regression, with SE or PBs as dependent factor and profession (in dummy variables with first pediatricians and second mental health professionals as comparison group), sex, age and years in profession as independent factors. Last, the barriers that the HCPs provided in the open-ended question were scored into categories, by two coders that aimed to remain as close as possible to the text.

\section{Results}

Table 1 summarizes the baseline characteristics of 578 participants. The number of missing determinants was low: Sex was missing for 13 participants $(2.2 \%)$, age for $5(0.9 \%)$, and years in profession for $5(0.9 \%)$. The male-female ratio differed significantly ( $p<0.01)$ between groups, with the largest percentage of males in the group of pediatricians $(33.3 \%, n=8)$ and the lowest percentage of males in the group of YHCNs (1.2\%, $n=3)$. Also, a significant $(p<0.01)$ age difference was found, with pediatricians being the oldest (mean age [SD] 50.5 [9.2] yrs) and dieticians being the youngest (37.6 [13.2] yrs). In addition, HCP's professional experience differed significantly ( $p=0.01$ ), with physiotherapists having the most experience (median [IQR] $17.0[6.5-27.5] \mathrm{yrs})$ and GPs having the least experience $(5.5[2.6-18.3] \mathrm{yrs})$.

Table 1

\section{Baseline characteristics of participants}

\begin{tabular}{|lll|}
\hline Male, N (\%) & 36 & $(.6 .4 \%)$ \\
\hline Age, Mean (SD) years & 43.1 & $(12.0)$ \\
\hline Profession, N (\%) & & \\
\hline General practitioners (GP) & 25 & $(4.3 \%)$ \\
\hline Youth health care physicians (YHCP) & 92 & $(15.9 \%)$ \\
\hline Youth health care nurses (YHCN) & 260 & $(45 \%)$ \\
\hline Pediatricians & 31 & $(5.4 \%)$ \\
\hline Mental health professionals & 51 & $(8.8 \%)$ \\
\hline Dieticians & 78 & $(13.5 \%)$ \\
\hline Physiotherapists & 41 & $(7.1 \%)$ \\
\hline Years in profession, Median [IQR] years & 11.0 & $(5.0-22.0)$ \\
\hline
\end{tabular}




\subsection{Self-efficacy}

Scores on SE were known for 554 HCPs (95.8\%) and are shown in Table 2. The mean score of the different groups of professionals ranged from 6.8 to 8.1. The overall mean was $7.2(S D=1.2)$. A significant interdisciplinary difference was found $(p<.001)$ : Pediatricians reported significantly higher scores on SE as compared to all other groups, except for dieticians and YHCPs. Adjusting for sex, age and years in profession did not change this. In addition, 38 (6.9\% of the total group) HCPs felt incapable (i.e. rated their SE $\leq 5$ ) to successfully address weight and lifestyle to children with overweight or obesity and their parents.

Table 2

Perceived self-efficacy and number of different barriers

\begin{tabular}{|c|c|c|c|c|c|c|c|}
\hline \multirow[b]{3}{*}{ Total group } & \multicolumn{3}{|c|}{ Self-efficacy } & \multirow{2}{*}{\multicolumn{2}{|c|}{$\begin{array}{l}\text { Number of different barriers } \\
\text { Median [IQR] }\end{array}$}} & \multirow[t]{2}{*}{ Do not discuss weight in $\geq 50 \%$ of cases } & \multirow{5}{*}{$\begin{array}{l}\text { SE was rated on a } \\
\text { scale of } 0-10 \text {. } \\
\text { Groups of HCPs were } \\
\text { ranked in order of } \\
\text { mean perceived SE } \\
\text { rating. A maximum of }\end{array}$} \\
\hline & \multicolumn{2}{|c|}{ Mean (SD) } & \multirow{2}{*}{$\begin{array}{l}\text { Rated } \leq 5 \\
6.9 \%\end{array}$} & & & & \\
\hline & 7.2 & $(1.2)$ & & 4.0 & {$[2.0-5.0]$} & $9.6 \%$ & \\
\hline Pediatricians & $8.1^{*}$ & (1.2) & $3.2 \%$ & $2.0 *$ & {$[1.0-4.0]$} & $12.9 \% *$ & \\
\hline Dieticians & 7.5 & $(1.1)$ & $2.8 \%$ & 4.0 & {$[2.75-5.0]$} & $5.3 \% *$ & \\
\hline YHCPS & 7.4 & $(1.1)$ & $5.5 \%$ & 5.0 & {$[3.0-6.0]$} & $5.4 \% *$ & reported. \\
\hline Mental health prof. & 7.2 & $(1.7)$ & $13.0 \%$ & $2.0 *$ & {$[1.0-4.0]$} & $18.0 \%$ & $\begin{array}{l}\text { Interdisciplinary } \\
\text { differences were }\end{array}$ \\
\hline YHCNs & 7.1 & $(1.0)$ & $6.5 \%$ & 4.0 & {$[3.0-6.0]$} & $2.3 \% *$ & analyzed post-hoc \\
\hline Physiotherapists & 6.9 & $(1.5)$ & $12.2 \%$ & 4.0 & {$[3.0-6.0]$} & $30.0 \%$ & with Bonferroni \\
\hline GPs & 6.8 & $(1.6)$ & $12.0 \%$ & 4.0 & {$[2.0-5.0]$} & $60 \%$ & significancy $(p<0.05)$ \\
\hline
\end{tabular}

asterisk.

\subsection{Perceived Barriers}

The number of different reported PBs was known for all 578 HCPs and ranged between 0 and 12, median 4.0 (see Figure 1, Table 2 and 3 ). Pediatricians reported significantly less PBs as compared to all other groups, except for mental health professionals. Mental health professionals perceived significantly less barriers as compared to YHCPs, YHCNs and physiotherapists. By adjusting for sex, age and years in profession the differences between pediatricians and dieticians became non-significant. All other interdisciplinary differences remained. The majority of HCPs ( $94.6 \%)$ reported that they perceive one or more barriers.

In total, $571 \mathrm{HCPs}(98.8 \%)$ answered the question whether they made the effort to discuss weight and lifestyle despite PBs. Overall, 55 HCPs (9.6\%), reported that they did not address weight and lifestyle in the majority of cases due to PBs. In addition, large inter-disciplinary differences were found. The majority of GPs (60\%) reported that they did not address this topic when applicable, which was significantly more often than pediatricians, dieticians, YHCNs and YHCPs. Moreover, mental health professional and physiotherapists reported significantly more often that they did not address this topic, as compared to dieticians, YHCNs and YHCPs.

HCPs that did not address weight and lifestyle in the majority of cases due to PBs rated their SE significantly lower (mean SE 6.3 [SD 1.40], p<0.001), as compared to the other HCPs who were likely to address this topic (mean SE 7.3 [SD 1.15]), but reported equal numbers of PBs. In total, $14.2 \%$ ( $n=82$ ) of all HCPs either rated their SE below 5 or reported that they did not address weight and lifestyle due to PBs in the majority of cases.

The professionals who did not address weight and lifestyle in the majority of the cases $(n=55,9.6 \%)$, were more likely to report the following PBs than professionals who were likely to address this topic: Not part of my job description $(p=0.001)$, not enough training in specific communication strategies $(p$ $=0.003)$, not enough knowledge about which words are best to use $(p<0.001)$, expectation that the child and/or parent will react negatively $(p=$ $0.01)$, discussing weight could stand in the way of having a good relationship with the child or parent $(p=0.004)$, and insufficient knowledge about the causes of overweight and obesity $(p=0.02)$. In contrast, professionals who almost always discuss weight and lifestyle reported more often as a PB: A child or parent with Dutch as a second language $(p=0.01)$, and discussing weight could be perceived as a negative judgement about the whole family ( $p$ $=0.01$ ).

\subsection{Additional Barriers}

In addition to the questionnaire, HCPs were given the 
opportunity to provide one or more additional PBs or other remarks. One hundred forty-eight HCPs (23.5\%) used this opportunity. Some barriers were already stated in the questionnaire.

Additional PBs were (ranked based on frequency): Other reasons for encounter than obesity $(n=23)$, parents who do not acknowledge the weight problem ( $n=15)$, perceiving resistance in the parents $(n=12)$, insufficient knowledge or insufficient skills (e.g. concerning motivational interviewing and not enough experience in general) $(n=10)$, perceiving a lack of motivation in the parents $(n=10)$, family with a non-Dutch culture ( $n=7)$, difficulty to address parenting issues $(n=6)$, previous attempts by the professional or other professional have failed $(n=4)$, individual differences, no 'one size fits all' $(n=3)$, afraid that the child and parent have heard it multiple times already from different professionals $(n=3)$, parents who feel that the professional is interfering with their personal life $(n=2)$, and insufficient confidence that discussing the weight will be successful $(n=1)$.

\section{Discussion And Conclusion}

The aim of the current study was to examine self-efficacy and perceived barriers of Dutch HCPs in regard to talking about weight and lifestyle when treating children with overweight or obesity and their parents, and assess interdisciplinary differences. On average, HCPs rated their self-efficacy fairly good (mean SE 7.2). However, 1 in 15 (6.9\%) rates their self-efficacy $\leq 5$, almost all HCPs (94.6\%) perceive at least one barrier and 1 in 10 (9.6\%) avoids talking about weight and lifestyle due to barriers. Moreover, HCPs from all 7 professions, overall 1 in 7 (14.2\%), reported that they felt incapable of addressing weight and lifestyle when treating children with overweight or obesity. Underlying barriers that were reported included both internal and external factors.

In our study, interdisciplinary differences were found: Pediatricians had the highest SE ratings and lowest number of PBs, in contrast to GPs with the lowest SE ratings and highest numbers of PBs. In addition, large intra-disciplinary differences were found, e.g. pediatricians rated their SE on average a 8.1 , however still 1 in $8(12.9 \%)$ pediatricians perceived to many barriers to address weight and lifestyle when treating children with overweight or obesity. In recent Canadian studies similar large interindividual differences within groups of pediatricians were reported $(16,17)$. It is important to know that the role of pediatricians in the Netherlands is different in comparison to other countries. Pediatricians in other countries also provide primary health care (18, 19), while in the Netherlands they are medical specialists and provide only secondary or tertiary care. The work of a pediatrician in other countries is more comparable to our GPs and YHCPs. These differences in tasks could lead to interdisciplinary differences in self-efficacy and perceived barriers, hampering direct comparisons between countries and healthcare systems. Moreover, the observation that SE ratings are relatively high, might not relate to their competence, but instead could also reflect unconscious incompetence. However, a recurring finding is that there is a rather high chance that a child with overweight or obesity comes across one or more professionals that do not feel secure about their capabilities in talking about weight and lifestyle and avoids the topic when discussing a patient's health $(6,9)$.

In the current study both external (i.e. task attributes and complexity, and the organization of health care), as well as internal determinants of self-efficacy (i.e. individual knowledge, skills and personality) were reported to form a barrier for optimal obesity care for children (13). Interestingly, in our study we found that HCPs who almost always discuss weight and lifestyle reported more often external barriers, whereas HPCs that perceive too many barriers to discuss this topic reported more often internal barriers and rated their self-efficacy significantly lower. Furthermore, many HCPs perceived more problems in talking about weight and lifestyle in cases when parents had overweight or obesity, and/or when they expected that the child and/or parent would react negatively. This relates to stigmatization of people with obesity that is present among the general public as well as among HCPs (20,21) and asks for education in communication strategies to address this sensitive topic (22), thereby improving HCP's perceived self-efficacy and reducing barriers (2, 14 , $15,23,24)$. Furthermore, the majority of doctors (GPs, YHCPs and pediatricians) reported that insufficient time is a barrier to talk about weight and lifestyle. This is a commonly reported barrier in other studies as well, and asks also for health delivery system changes $(2,14,15,23,24)$. Next to education, an improved and sustainable financial and infrastructural framework is necessary to reduce the obesity stigma, improve obesity care for children, and positively impact HCP's perceived self-efficacy and barriers $(6,9,20,21)$.

The current study has some limitations. First, the sample sizes per subgroup of professionals were limited. Especially, the GPs and pediatricians were underrepresented. Moreover, within one subgroup, colleagues from the same discipline though possibly from different levels of care (i.e. mental health professionals working in either primary, secondary or tertiary care) were grouped. Therefore discipline-specific results should be interpreted with caution. Second, there is a high chance of selection bias, i.e. some professionals might have been more inclined to fill in the questionnaire than others. Third, it is possible that professionals gave socially desirable answers. Fourth, we asked HCPs to report perceived capabilities and have not evaluated correlated behavior or practical skills.

The study also has strong points. First, the inclusion of 7 different groups of professionals, covering all levels of obesity care within both the medical and social domain. In addition, it is the first study that investigated self-efficacy and perceived barriers in the Dutch healthcare setting, among HCPs in regard to talking about weight and lifestyle when treating children with overweight or obesity.

To conclude, Dutch HCPs that work in obesity care for children rate their self-efficacy on average fairly good. However, still a child with overweight or obesity has a high chance of coming across an HCP that feels incapable to address weight and lifestyle in a conversation (1 in 7, $14.2 \%$, for each time facing a new HCP). Accordingly, for a subgroup of HPCs major improvements in the health delivery system, including educational, infrastructural and financial factors, are necessary to overcome both internal and external barriers that were reported to potentially result in avoidance to discuss weight and lifestyle when treating children with overweight or obesity. To optimally target such improvements, the relation between SE ratings, knowledge and skills, i.e. the quality of care, needs to be evaluated. Moreover, future research is necessary to study why some HCPs perceive barriers yet feel capable to address the topic, whereas others avoid the topic when appropriate, despite a similar number of perceived barriers.

Page 5/9 


\section{Abbreviations}

GP: General Practitioner; HCP: Healthcare Professional; PB: Perceived barrier; SE: Self-efficacy; YHCP: Youth Health-care Physician; YHCN: Youth Healthcare Nurse

\section{Declarations}

\section{Ethics approval and consent to participate}

Signed, written informed consent was obtained and all methods were performed in accordance with the relevant guidelines and regulations. The institutional review board of the VU Medical Center waived the requirement of full medical ethical approval.

\section{Consent for publication}

Not applicable

\section{Availability of data and materials}

The datasets generated and analyzed during the current study are not publicly available, instead these are available from the corresponding author on reasonable request, due to the presence of indirect identifiers, making it impossible for health-care professionals of certain subgroups to stay completely anonymous.

\section{Competing interests}

The authors declare no conflict of interest.

\section{Funding}

This work was supported by the Dutch Ministry of Health, Welfare and Sport [grant number VWS: 324043]

\section{Authors' contributions}

The authors confirm contribution to the paper as follows: Study conception and design: RC, JS and JH; data collection: RC; analysis and interpretation of results: $\mathrm{BV}, \mathrm{RC}, \mathrm{JS}$ and $\mathrm{JH}$; draft manuscript $\mathrm{BV}$ and $\mathrm{RC}$. All authors reviewed the results and approved the final version of the manuscript.

\section{Acknowledgements}

Not applicable

\section{Authors' information}

Not applicable

\section{References}

1. Zantinge EM, Hendriks C. Kinderen met overgewicht en obesitas naar leeftijd 2020 https://www.volksgezondheidenzorg.info/onderwerp/overgewicht/cijfers-context/huidige-situatie\#node-overgewicht-kinderen: RIVM; 2020 [updated 03-11-2021.

2. Yarborough BJ, DeBar LL, Wu P, Pearson J, Stevens VJ. Responding to pediatric providers' perceived barriers to adolescent weight management. Clin Pediatr (Phila). 2012;51(11):1063-70.

3. Koetsier LW, van Mil MMA, Eilander MMA, van den Eynde E, Baan CA, Seidell JC, et al.Conducting a psychosocial and lifestyle assessment as part of an integrated care approach for childhood obesity: experiences, needs and wishes of Dutch healthcare professionals. BMC Health Serv Res.

$2021 ; 21(1): 611$

4. Mikhailovich K, Morrison P. Discussing childhood overweight and obesity with parents: a health communication dilemma. Journal of Child Health Care. 2007;11(4):311-22. 
5. Auckburally S, Davies E, Logue J. The Use of Effective Language and Communication in the Management of Obesity: the Challenge for Healthcare Professionals. Current Obesity Reports. 2021;10(3):274-81.

6. Bradbury D, Chisholm A, Watson PM, Bundy C, Bradbury N, Birtwistle S. Barriers and facilitators to health care professionals discussing child weight with parents: A meta-synthesis of qualitative studies. Br J Health Psychol. 2018;23(3):701-22.

7. Sjunnestrand M, Nordin K, Eli K, Nowicka P, Ek A. Planting a seed - child health care nurses' perceptions of speaking to parents about overweight and obesity: a qualitative study within the STOP project. BMC Public Health. 2019;19(1):1494.

8. Serban CL, Putnoky S, Ek A, Eli K, Nowicka P, Chirita-Emandi A. Making Childhood Obesity a Priority: A Qualitative Study of Healthcare Professionals' Perspectives on Facilitating Communication and Improving Treatment. Front Public Health. 2021;9:652491.

9. Srivastava G, Browne N, Kyle TK, O'Hara V, Browne A, Nelson T, et al. Caring for US Children: Barriers to Effective Treatment in Children with the Disease of Obesity. Obesity (Silver Spring). 2021;29(1):46-55.

10. Keyworth C, Epton T, Goldthorpe J, Calam R, Armitage CJ. Delivering Opportunistic Behavior Change Interventions: a Systematic Review of Systematic Reviews. Prev Sci. 2020(21):319-31.

11. Bandura A. Self-efficacy: toward a unifying theory of behavioral change. Psychol Rev. 1977;84(2):191-215.

12. Godin G, Bélanger-Gravel A, Eccles M, Grimshaw J. Healthcare professionals' intentions and behaviours: a systematic review of studies based on social cognitive theories. Implement Sci. 2008;3:36.

13. Gist ME, Mitchell TR. Self-Efficacy: A Theoretical Analysis of Its Determinants and Malleability. The Academy of Management Review. 1992;17(2):183-211.

14. Mata Á NS, de Azevedo KPM, Braga LP, de Medeiros G, de Oliveira Segundo VH, Bezerra INM, et al. Training in communication skills for self-efficacy of health professionals: a systematic review. Hum Resour Health. 2021;19(1):30.

15. Silber M, Weiss L, Sharaf S, Wang Y, Hager E, Carter R. Pediatric Residency Obesity and Overweight Training Curricula: A Systematic Review. Glob Pediatr Health. 2020;7:2333794x20928215.

16. Patel BP, Hadjiyannakis S, Clark L, Buchholz A, Noseworthy R, Bernard-Genest J, et al. Evaluation of a Pediatric Obesity Management Toolkit for Health Care Professionals: A Quasi-Experimental Study. Int J Environ Res Public Health. 2021;18(14).

17. Bernard-Genest J, Chu L, Dettmer E, Walsh CM, McPherson AC, Strub J, et al. Talking About Weight With Families-Helping Health Care Professionals Start the Conversation: A Nonrandomized Controlled Trial. Clin Pediatr (Phila). 2020;59(9-10):910-7.

18. Wilfley DE, Staiano AE, Altman M, Lindros J, Lima A, Hassink SG, et al. Improving access and systems of care for evidence-based childhood obesity treatment: Conference key findings and next steps. Obesity (Silver Spring). 2017;25(1):16-29.

19. Wammes J, Jeurissen P, Westert G, Tanke M. The Dutch health care system: International Profiles of Health Care Systems https://www.commonwealthfund.org/: The Commonwealth Fund; 2020

20. Rubino F, Puhl RM, Cummings DE, Eckel RH, Ryan DH, Mechanick Jl, et al.Joint international consensus statement for ending stigma of obesity. Nat Med. 2020;26(4):485-97.

21. van der Voorn B, Camfferman R, Seidell JC, Puhl RM, Halberstadt J. Weight-Biased Attitudes about Pediatric Patients with Obesity in Dutch Health Care Professionals from Seven Different Professions. Under review at Journal of Child Health Care. 2022.

22. Stuij M, van Maarschalkerweerd PEA, Seidell JC, Halberstadt J, Dedding C. Youth perspectives on weight-related words used by healthcare professionals: A qualitative study. Child Care Health Dev. 2020;46(3):369-80.

23. Shue CK, Whitt JK, Daniel L, Shue CB. Promoting conversations between physicians and families about childhood obesity: evaluation of physician communication training within a clinical practice improvement initiative. Health Communication. 2016;31(4):408-16.

24. Mastrocola MR, Roque SS, Benning LV, Stanford FC. Obesity education in medical schools, residencies, and fellowships throughout the world: a systematic review. Int J Obes (Lond). 2020;44(2):269-79.

\section{Table}

Table 3

\section{Perceived Barriers by Group of Professionals}




\begin{tabular}{|c|c|c|c|c|c|c|c|c|c|c|c|c|c|c|c|c|}
\hline & \multicolumn{2}{|c|}{$\begin{array}{l}\text { General } \\
\text { practitioners }\end{array}$} & \multicolumn{2}{|c|}{$\begin{array}{l}\text { Youth } \\
\text { Health } \\
\text { Care } \\
\text { Physicians }\end{array}$} & \multicolumn{2}{|c|}{$\begin{array}{l}\text { Youth } \\
\text { Health Care } \\
\text { Nurses }\end{array}$} & \multicolumn{2}{|c|}{ Pediatricians } & \multicolumn{2}{|c|}{$\begin{array}{l}\text { Mental } \\
\text { health } \\
\text { professionals }\end{array}$} & \multicolumn{2}{|c|}{ Dieticians } & \multicolumn{2}{|c|}{ Physiotherapists } & \multicolumn{2}{|c|}{ Total } \\
\hline & $\mathrm{N}$ & $\%$ & $\mathrm{~N}$ & $\%$ & $\mathrm{~N}$ & $\%$ & $\mathrm{~N}$ & $\%$ & $\mathrm{~N}$ & $\%$ & $\mathrm{~N}$ & $\%$ & $\mathrm{~N}$ & $\%$ & $\mathrm{~N}$ & $\%$ \\
\hline Insufficient time & 15 & $60 \%$ & 45 & $49 \%$ & 95 & $37 \%$ & 15 & $48 \%$ & 8 & $16 \%$ & 30 & $39 \%$ & 7 & $17 \%$ & 215 & $37 \%$ \\
\hline $\begin{array}{l}\text { Is not stated in my } \\
\text { job description }\end{array}$ & 1 & $4 \%$ & 0 & $0 \%$ & 1 & $0.4 \%$ & 0 & $0 \%$ & 3 & $6 \%$ & 3 & $4 \%$ & 6 & $15 \%$ & 14 & $2 \%$ \\
\hline $\begin{array}{l}\text { Insufficient care to } \\
\text { refer to }\end{array}$ & 5 & $20 \%$ & 38 & $41 \%$ & 61 & $24 \%$ & 17 & $55 \%$ & 5 & $10 \%$ & 7 & $9 \%$ & 4 & $10 \%$ & 137 & $24 \%$ \\
\hline $\begin{array}{l}\text { Child or parent } \\
\text { with Dutch as a } \\
\text { second language. }\end{array}$ & 12 & $48 \%$ & 46 & $50 \%$ & 126 & $49 \%$ & 7 & $23 \%$ & 14 & $28 \%$ & 33 & $42 \%$ & 15 & $37 \%$ & 253 & $44 \%$ \\
\hline $\begin{array}{l}\text { Child or parent } \\
\text { with low cognitive } \\
\text { abilities }\end{array}$ & 11 & $44 \%$ & 38 & $41 \%$ & 99 & $38 \%$ & 8 & $26 \%$ & 9 & $18 \%$ & 28 & $36 \%$ & 14 & $34 \%$ & 207 & $36 \%$ \\
\hline $\begin{array}{l}\text { Not enough } \\
\text { training in specific } \\
\text { communication } \\
\text { strategies }\end{array}$ & 7 & $28 \%$ & 18 & $20 \%$ & 44 & $17 \%$ & 1 & $3 \%$ & 9 & $18 \%$ & 18 & $23 \%$ & 13 & $32 \%$ & 110 & $19 \%$ \\
\hline My own weight & 1 & $4 \%$ & 1 & $1 \%$ & 10 & $4 \%$ & 0 & $0 \%$ & 2 & $4 \%$ & 3 & $4 \%$ & 1 & $2 \%$ & 18 & $3 \%$ \\
\hline $\begin{array}{l}\text { Not enough } \\
\text { knowledge about } \\
\text { which words are } \\
\text { best to use }\end{array}$ & 7 & $28 \%$ & 10 & $11 \%$ & 34 & $13 \%$ & 1 & $3 \%$ & 4 & $8 \%$ & 16 & $21 \%$ & 14 & $34 \%$ & 86 & $15 \%$ \\
\hline $\begin{array}{l}\text { Afraid that } \\
\text { discussing the } \\
\text { weight of the child } \\
\text { will damage the } \\
\text { child emotionally }\end{array}$ & 6 & $24 \%$ & 24 & $26 \%$ & 78 & $30 \%$ & 3 & $10 \%$ & 14 & $28 \%$ & 34 & $44 \%$ & 19 & $46 \%$ & 178 & $31 \%$ \\
\hline $\begin{array}{l}\text { Difficult to make } \\
\text { children and } \\
\text { parents realize } \\
\text { what the impact is } \\
\text { of } \\
\text { overweight/obesity } \\
\text { on health }\end{array}$ & 3 & $12 \%$ & 18 & $20 \%$ & 51 & $20 \%$ & 0 & $0 \%$ & 7 & $14 \%$ & 17 & $22 \%$ & 5 & $12 \%$ & 101 & $18 \%$ \\
\hline $\begin{array}{l}\text { Negative } \\
\text { experiences with } \\
\text { discussing weight } \\
\text { and lifestyle }\end{array}$ & 2 & $8 \%$ & 33 & $36 \%$ & 52 & $20 \%$ & 2 & $7 \%$ & 6 & $12 \%$ & 2 & $3 \%$ & 2 & $5 \%$ & 99 & $17 \%$ \\
\hline $\begin{array}{l}\text { Expectation that } \\
\text { the child and/or } \\
\text { parent will react } \\
\text { negatively }\end{array}$ & 12 & $48 \%$ & 46 & $50 \%$ & 101 & $39 \%$ & 5 & $16 \%$ & 12 & $24 \%$ & 21 & $27 \%$ & 20 & $49 \%$ & 217 & $38 \%$ \\
\hline $\begin{array}{l}\text { Discussing weight } \\
\text { could stand in the } \\
\text { way of having a } \\
\text { good relationship } \\
\text { with the child or } \\
\text { parent }\end{array}$ & 6 & $24 \%$ & 17 & $19 \%$ & 43 & $17 \%$ & 2 & $7 \%$ & 13 & $26 \%$ & 14 & $18 \%$ & 15 & $37 \%$ & 110 & $19 \%$ \\
\hline $\begin{array}{l}\text { Discussing weight } \\
\text { could be perceived } \\
\text { as a negative } \\
\text { judgement about } \\
\text { the whole family }\end{array}$ & 12 & $48 \%$ & 46 & $50 \%$ & 126 & $49 \%$ & 7 & $23 \%$ & 14 & $28 \%$ & 33 & $42 \%$ & 15 & $37 \%$ & 253 & $43.8 \%$ \\
\hline $\begin{array}{l}\text { Parents with } \\
\text { overweight or } \\
\text { obesity }\end{array}$ & 9 & $36 \%$ & 39 & $42 \%$ & 125 & $48 \%$ & 3 & $10 \%$ & 13 & $26 \%$ & 30 & $39 \%$ & 20 & $49 \%$ & 239 & $41 \%$ \\
\hline $\begin{array}{l}\text { Insufficient } \\
\text { knowledge about } \\
\text { the causes of } \\
\text { overweight and } \\
\text { obesity }\end{array}$ & 1 & $4 \%$ & 0 & $0 \%$ & 19 & $7 \%$ & 0 & $0 \%$ & 5 & $10 \%$ & 3 & $4 \%$ & 3 & $8 \%$ & 31 & $5 \%$ \\
\hline
\end{tabular}




\section{Figures}

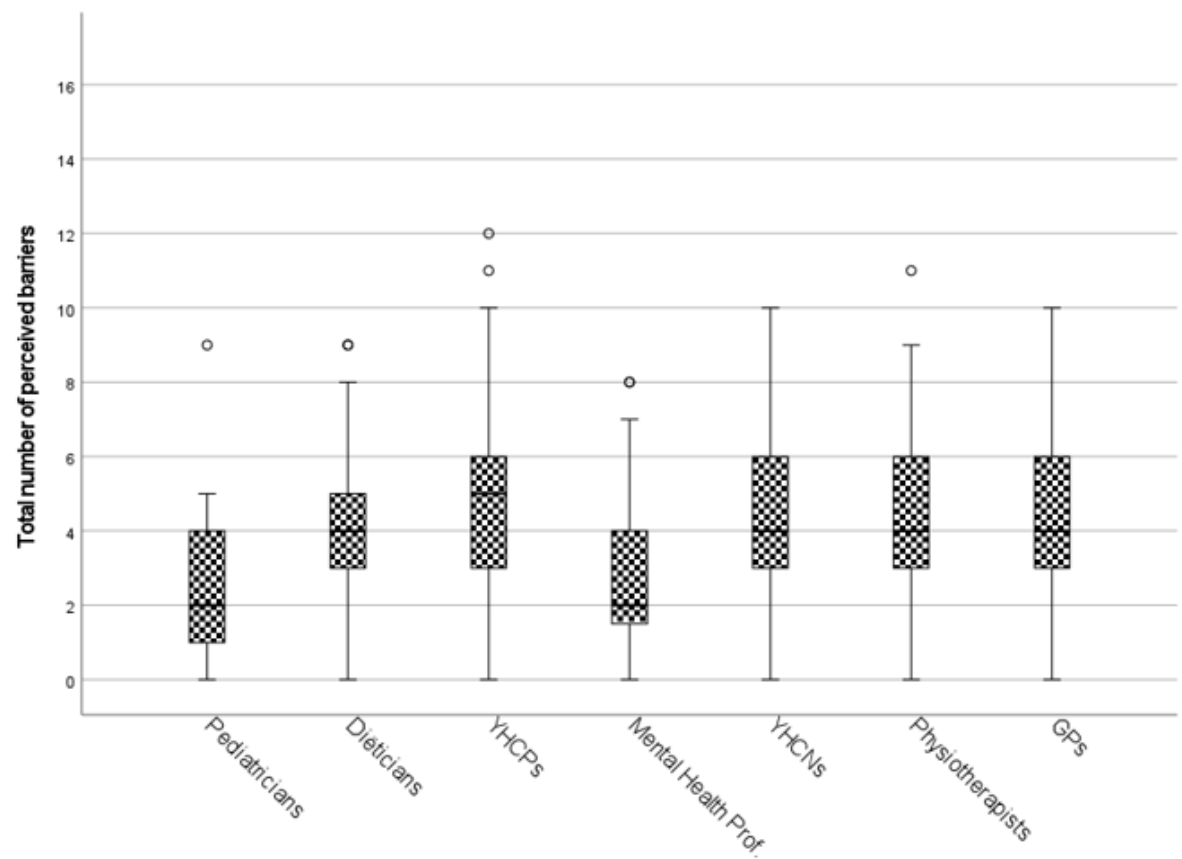

Figure 1

Boxplot of interdisciplinary differences in perceived barriers. HCP groups were ranked in order of perceived self-efficacy rating. A maximum of 17 barriers could be reported.

\section{Supplementary Files}

This is a list of supplementary files associated with this preprint. Click to download.

- Supplementaryfile1.docx 